\title{
XPS characterization of (copper-based) coloured stains formed on limestone surfaces of outdoor Roman monuments
}

\author{
Anna Maria Salvi ${ }^{1 *}$, Fausto Langerame ${ }^{1 \dagger}$, Andrea Macchia $^{2 \dagger}$, Maria Pia Sammartino ${ }^{2 \dagger}$, Marisa Laurenzi Tabasso ${ }^{2 \dagger}$ \\ From CMA4CH 2010: Multivariate Analysis and Chemometry to Cultural Heritage and Environment \\ Taormina, Italy. 26-29 September 2010
}

\begin{abstract}
Limestone basements holding bronzes or other copper alloys artefacts such as sculptures, decorations and dedicatory inscriptions are frequently met both in modern and ancient monuments. In outdoor conditions, such a combination implies the corrosion products of the copper based alloy, directly exposed to rainwater, will be drained off and migrate through the porous surfaces, forming stains of different colours and intensities, finally causing the limestone structures to deteriorate.

In this work we have analysed samples from two modern limestone monuments in Rome, the Botticino surfaces of the 'Vittoriano' (by G.Sacconi, 1885-1911- Piazza Venezia) and the travertine basement of the 'Statua dello Studente' (by A. Cataldi, 1920- University city, La Sapienza), and focussed our investigation on the chemical composition of the copperstained zones using XPS (X-ray Photoelectron Spectroscopy) as a surface-specific technique.

Based on observations reporting on the structure and bonding at the calcite surfaces we have identified copper complexes and mixed calcium/copper carbonates associated with the stains, as well as the chemical state of other elements therein included, and related the compositional changes with differences in chromatic characteristics and sampling locations.
\end{abstract}

\section{Background}

Outdoor bronzes are subjected to continual corrosion and dissolution processes, as well reported in literature [1-3]: associated with these processes are the coloured stains often observed on stone surfaces of outdoor monuments as the results of leaching from the attached bronze artefacts exposed to rainfall. It is common, in fact, that the corrosion products, dissolved and washed by rain, can reach portions of the nearby stone surfaces. Since all stones are, to various extents, porous, the rainwater laden with corrosion products enters the capillary net and when the stone starts to dry, those products deposited in a sub-surface volume are giving rise to efflorescence and the appearance of stained patches.

\footnotetext{
* Correspondence: anna.salvi@unibas.it

+ Contributed equally

'University of Basilicata, Chemistry Department, Viale Ateneo Lucano 10, 85100 Potenza, Italy

Full list of author information is available at the end of the article
}

The staining phenomena are not only perceived as an aesthetic problem confined to surfaces but also as promoters of a gradual deterioration that over the long term [4] reduces the legibility of the artefacts and deprives those monuments of their intrinsic (historical, religious or political) value.

It is generally accepted that the main constituent of the corrosion products from bronzes consists of $\mathrm{Cu}$ (II) salts $[5,6]$, however, the corrosion behaviour depends both on the specific environment and on the alloy characteristics $[6,7]$ and, therefore, the colour of the copper-based stains is certainly influenced by the presence of associated elements contributing to the weathering process.

In order to eliminate or reduce the damage produced by these patches, suitable cleaning procedures are required that would assure the removal of the surface stain without being too aggressive towards the underneath stone components that, in the case of marble and limestone, are 
mostly calcite and dolomite (calcium carbonate and calcium and magnesium carbonate respectively).

Research work [8-10] carried at the University of Rome is aimed at setting up a cleaning procedure suitable for architectural surfaces and sculptures, based on different operative phases: a) physical-chemical characterization of the patches with combined analytical techniques; b) laboratory test of different chemicals potentially useful for removing the staining products without damaging the stone substrate; c) 'in situ' cleaning with procedures selected in phase $b$ ).

Each operative phase should be preparatory to the next one however the experiments are performed iteratively and interactively using continuous feedback controls in order, hopefully, to optimize the whole procedure by means of successive approximations.

This paper deals with phase a) contributing with surface analyses to the physical-chemical characterization already in progress with the aid of combined analytical techniques, including also statistical evaluation by PCA (Principal Component Analysis) [10]. An accurate outcome from phase a) is the necessary start for the success of the subsequent phases, clearly taking into account the anticipated results of phases b) and c), as already said.

In particular, two modern limestone monuments in Rome, the 'Vittoriano' (by G. Sacconi, 1885-1911, Piazza Venezia) and the basement of the 'Statua dello Studente' (by A. Cataldi, 1920, University city, La Sapienza) were studied using XPS (X-ray Photoelectron Spectroscopy) as an analytical mean of investigations.

XPS, the spectroscopic technique most suitable for surface and near- surface analyses of solid compounds, provides elemental, speciation and semi-quantitative analysis at the nanometres scale, as will be explained in the next sections and, more in details, in additional file 1.

In the near future, for the completion of this study, the XPS results as elaborated in this paper will be further rationalized after comparison with results obtained in parallel with Optical Microscopy, X-ray diffraction, Electronic Microscopy combined with Fluorescence analysis (EDXRF) and Micro-Raman spectroscopy [work in progress].

\section{Methods}

The wide-angle views of the two Roman monuments here investigated, the Student's Statue (University 'La Sapienza') and the 'Vittoriano' (Piazza Venezia), are reported in Figures 1a-b and 1c-d, respectively.

Concerning the sampling for XPS analyses, criteria established by the Standards currently in use for the cultural heritage diagnostic were followed: samples of different colours and location were utilized either as small fragments already detached or in form of powders gently 'scraped' from the stained surfaces.

The fragments and powders were stored in inert plastic containers, properly plugged (to avoid further contaminants) and tagged with a number indicating the sampling zone: specific details of these zones are given where appropriate in the results section.

The XPS spectra were acquired with a Leybold spectrometer (LH X1) using the achromatic AlKa (1486.6 eV) and $\mathrm{MgK \alpha}(1253.6 \mathrm{eV})$ double source at a constant power of $260 \mathrm{~W}$.

Wide and detailed spectra were collected using the FAT (fixed analyzer transmission) mode of operation with a Pass Energy of $50 \mathrm{eV}$ and a channel width of 1.0 and 0.1 $\mathrm{eV}$, respectively. The samples were mounted on the sample holder using a double-sided adhesive copper tape and then transferred to the analysis chamber where the vacuum was always better than $10^{-7} \mathrm{~Pa}$. Care was taken to be sure that no signals from the adhesive tape were visible on the wide spectra.

The wide spectra of each sample were first acquired as a general survey: once the elements composing the sample are identified, the detailed region for each element was then acquired at higher resolution for quantitative (peaks areas) and speciation (chemical states) analysis.

The acquired data were elaborated with a curve-fitting program, NewGoogly $[11,12]$ and the obtained results reported in the tables. The peak assignments (uncertainty on BEs of $+/-0.2 \mathrm{eV}$ ) refer to literature data and to the NIST standard reference database available on line (http://srdata.nist.gov/xps/). Peak areas were converted to atomic per cent composition (At\%) using established procedures and the appropriate sensitivity factors (SF) $[13,14]$ to assure the correct elemental mass balance, in the limit of our accuracy [13,14]. The energy scales of the XPS figures reported in this paper are not corrected for surface charging but the peak assignments (Binding Energies, BEs), as reported in the tables, are referenced to $\mathrm{C} 1 \mathrm{~s}$ aliphatic carbon, as an internal standard, set at $285.0 \mathrm{eV}$. The wide spectra are reported, as acquired, in kinetic energy, whereas the energy scales of the detailed regions are converted to binding energy so as to facilitate comparison of the curve fitted results with literature data.

\section{Additional materials}

A brief description of the basic principles on which XPS is based is provided in Additional File 1 together with information on spectra features and data elaboration.

For the "Vittoriano" samples, supplementary figures, showing $\mathrm{C} 1 \mathrm{~s}, \mathrm{Cu} 2 \mathrm{p} 3 / 2, \mathrm{O} 1 \mathrm{~s}$ and $\mathrm{Ca} 2 \mathrm{p}$ curve-fitted regions, are added as Additional files 2, 3, 4, with the figures caption included. 


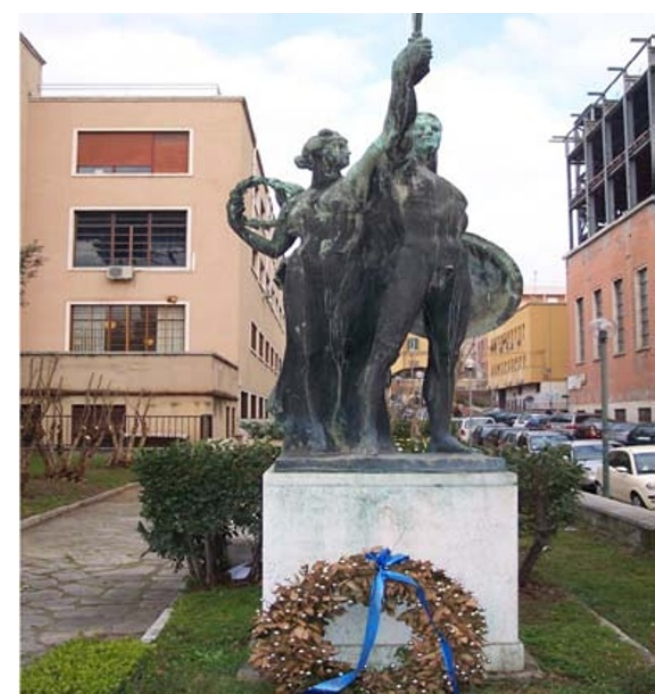

a)

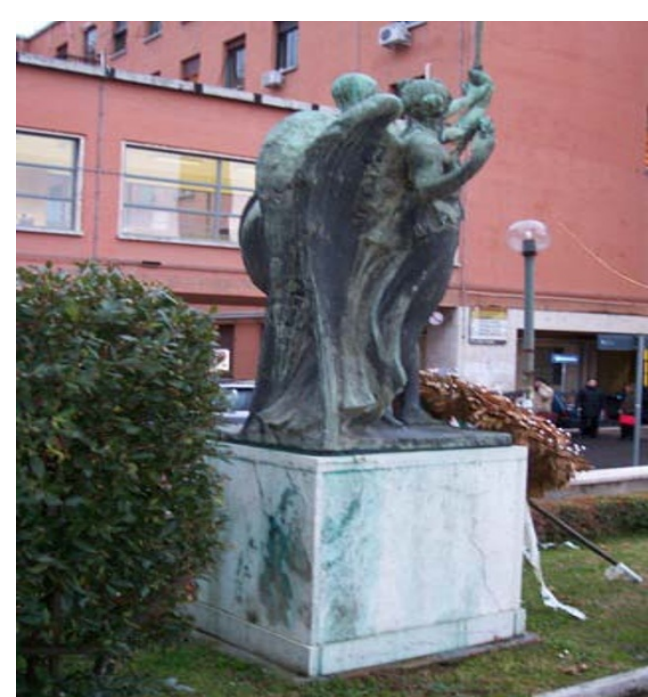

b)

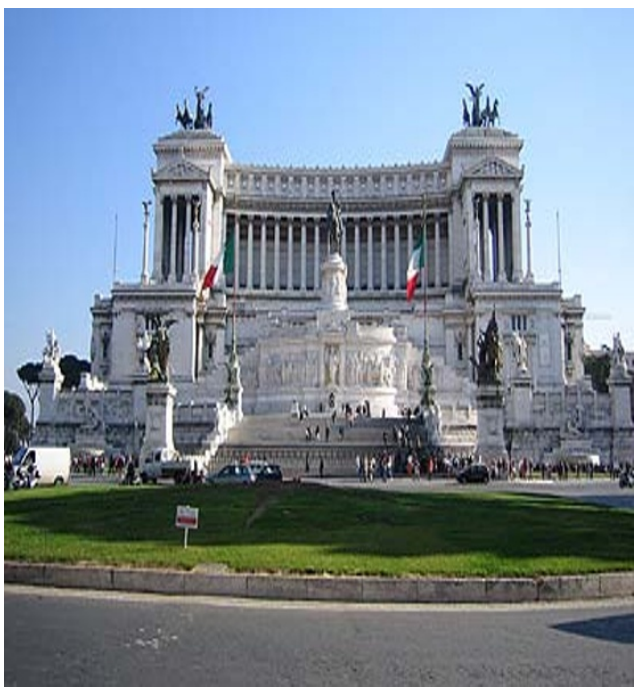

c)

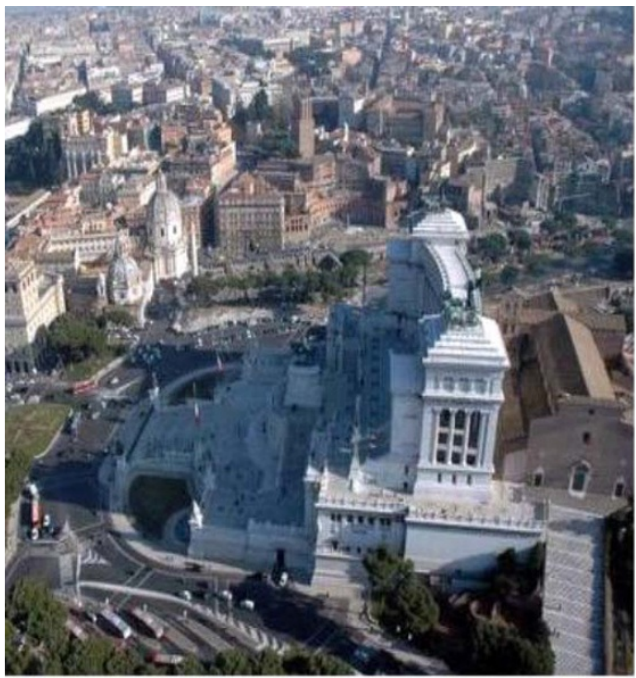

d)

Figure 1 Enlarged views of the two studied monuments in Rome. (a) and (b) 'Statua dello Studente' (by A.Cataldi, 1920- University city, La Sapienza); (c) and (d) Vittoriano' (by G.Sacconi, 1885-1911- Piazza Venezia).

\section{Results and discussion}

\section{'Statua dello Studente'}

The XPS wide spectrum in Figure 2a, acquired with $\mathrm{MgK} \alpha$, is representative of the powdered samples taken from both green and grey zones of the travertine basement where the sampling of the student's statue was performed, as shown in Figures $2 \mathrm{~b}$ and $\mathrm{c}$. The labels on the wide spectrum indicate the elements detected and the X-rays induced processes. The red-labelled peaks are directly associated to the photo-emitted electrons (XPS) while the black-labelled peaks (Auger peaks) are due to relaxation processes that follow photoemission always present in XPS spectra (X-AES, X-ray induced Auger Electron Spectroscopy) $[13,14]$. The utility of both signals, in particular of the Auger parameter $\alpha^{\prime}$ based on their relative interval in kinetic energy, will be soon evident.

The most significant detailed spectra are respectively shown in Figures 3 - 4 for the two zones together with the weighted percentages, Wt\%, of the surface compounds that better represent the results, obtained by curve fitting, summarized in Table 1.

The relative elemental compositions, At\%, derived from peak areas are reported for semi-quantitative analysis and Binding Energy, BE, from the peak positions, for qualitative and speciation analysis.

For both zones, the same main elements with similar chemical states were seen to compose the coloured stains. Given the close location of the two zones in the travertine basement this is not surprising, however, 


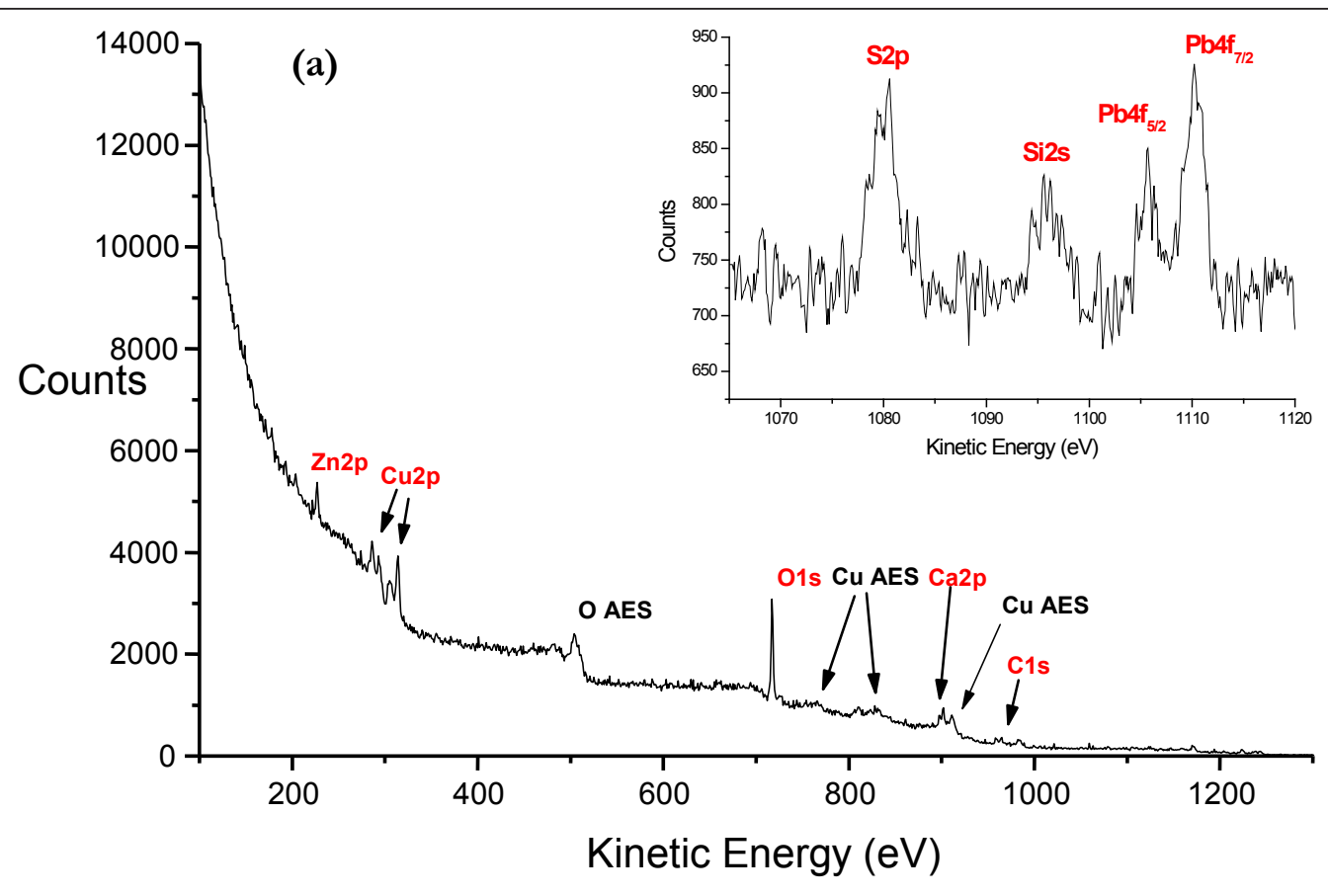

(b)

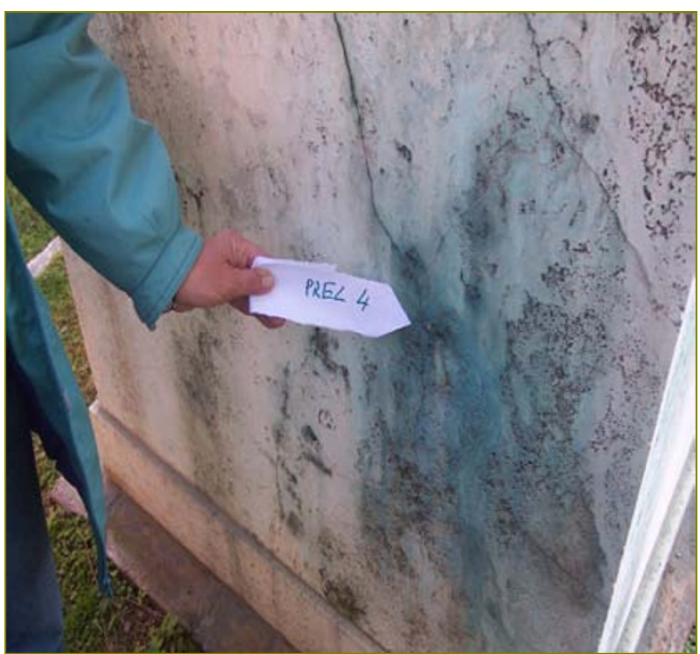

(c)

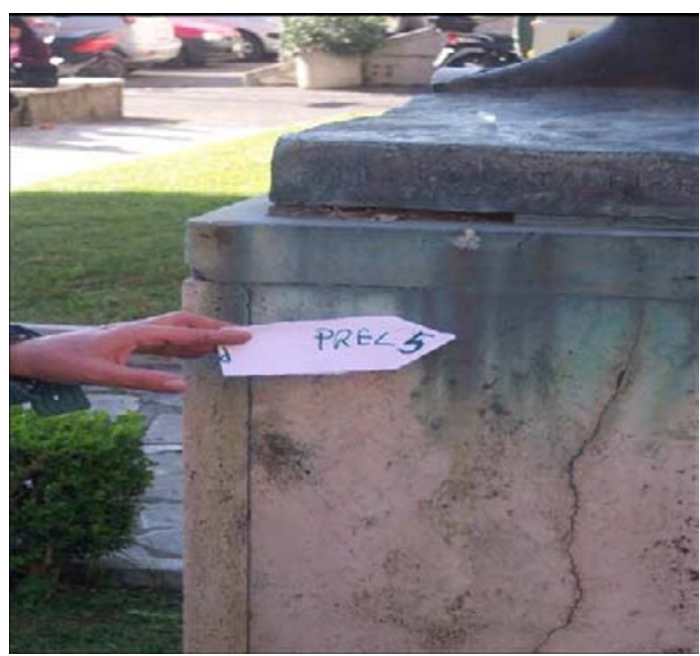

Figure 2 Typical XPS wide spectrum of samples taken from the "Statua dello Studente"(a). Detailed images of the green (b) and grey (c) sampling zones;

differences in the relative abundance of similar compounds, their degree of hydration and the amount of ubiquitous carbonaceous particulates, seem, in concert, responsible for these colour variations and could be taken as indicative of different surface processes taking place at the calcite surface by the action of local corrosion products drained from the statue together with environmental pollutants.

Based on results from curve-fitting, using an XPS online database and cited references, we have made the assignments for each spectral region and cross-checked the peak areas through a combined mass balance i.e. the 

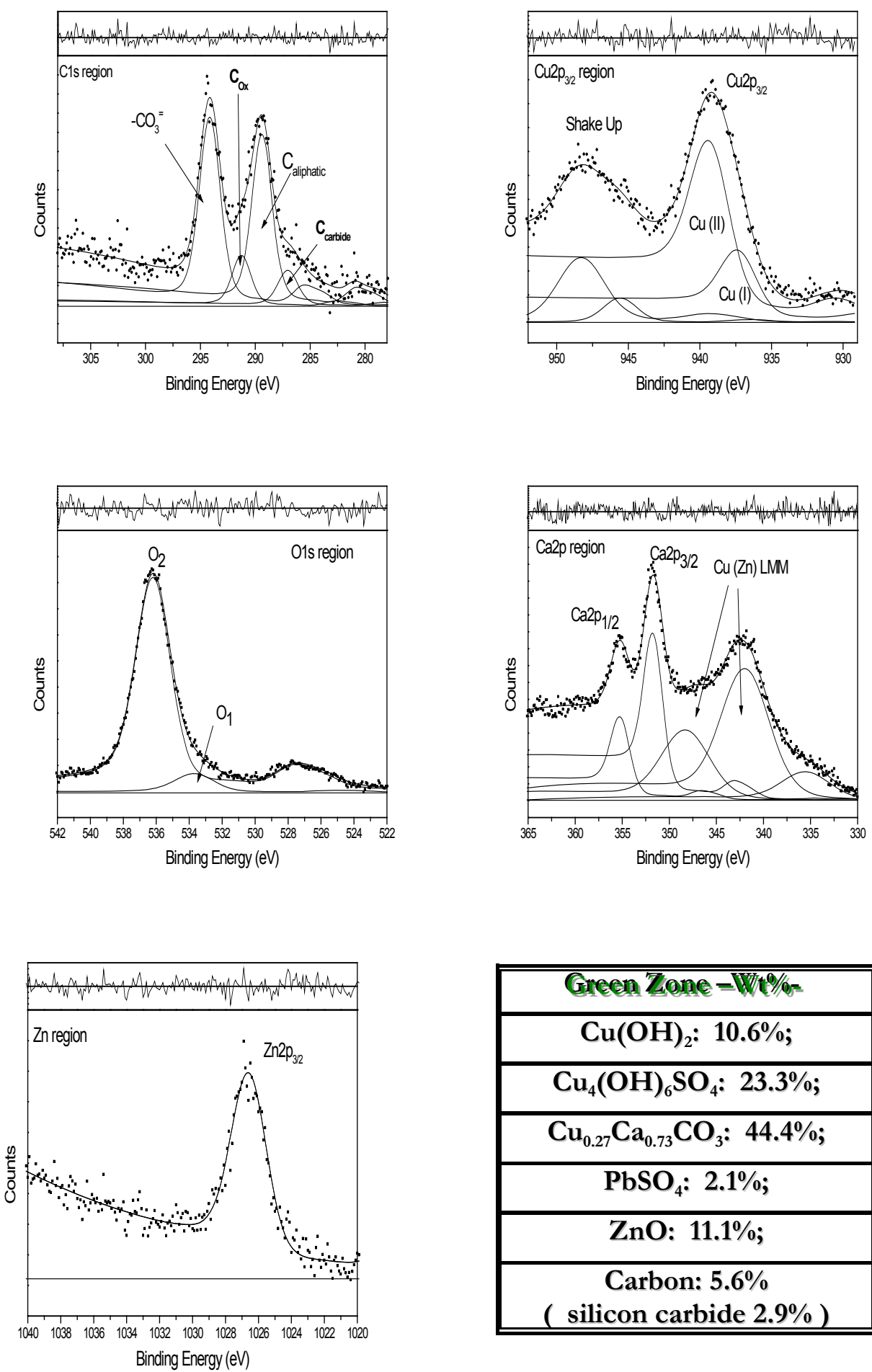

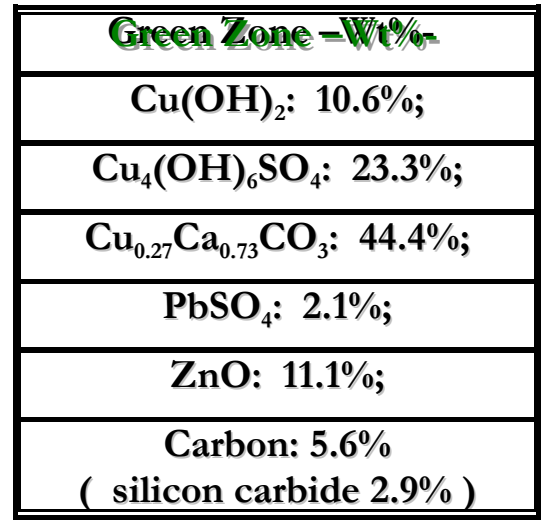

Figure 3 "Statua dello Studente": C1s, Cu2p3/2, O1s, Ca2p and Zn2p3/2 curve-fitted regions of the green zone and Wt\% derived from fitting results reported in Table 1.

total area of oxygen from the $\mathrm{O} 1 \mathrm{~s}$ spectrum to be balanced, in the limit of our accuracy, $[13,14]$ against all the oxygen-containing species, in order to confirm the compounds stoichiometry.
C1s

The carbon region, $\mathrm{C} 1 \mathrm{~s}$, was curve-fitted with four peaks both for the green and grey zones: see relevant Figures 3-4. 

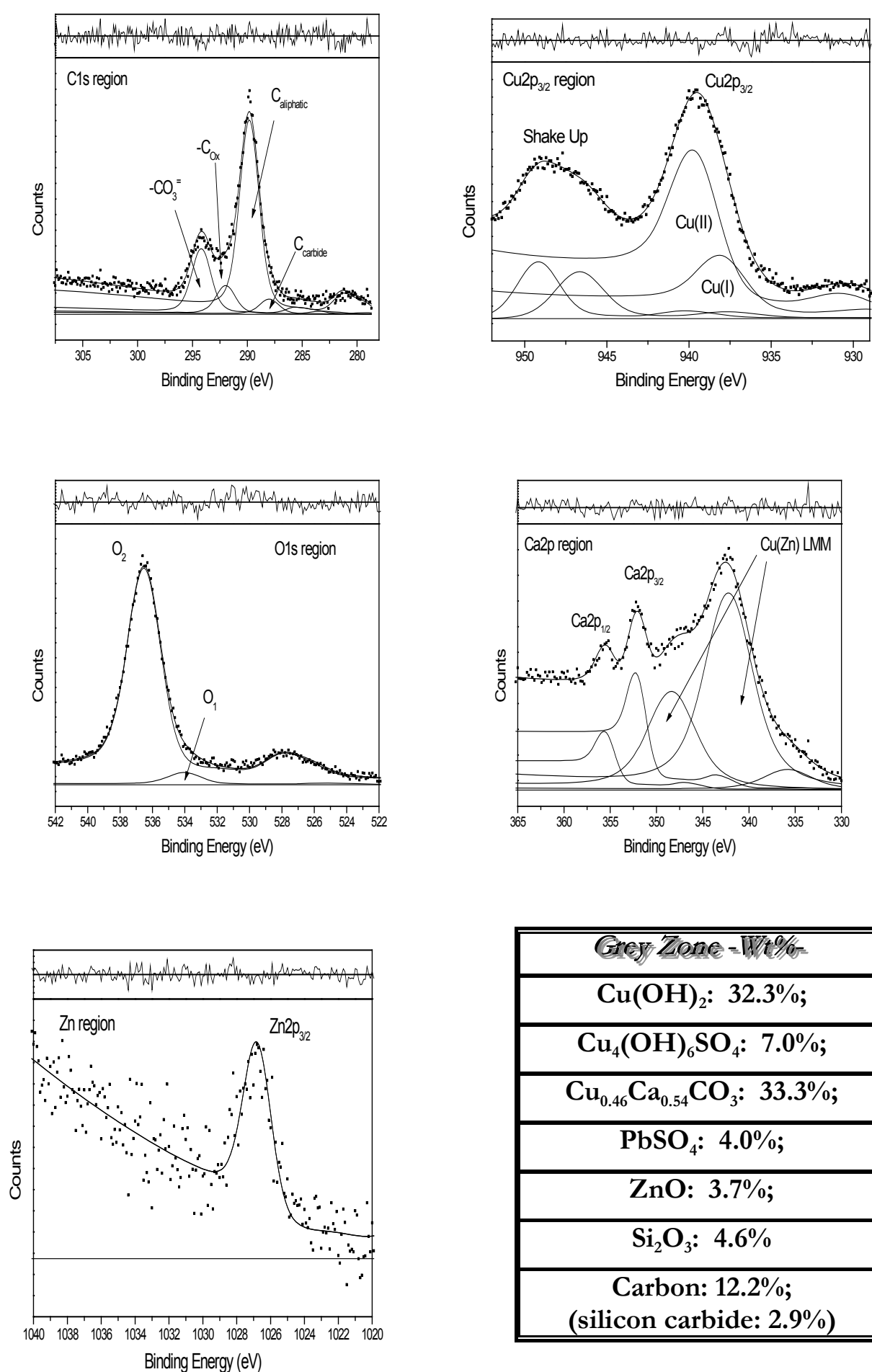

\begin{tabular}{|c|}
\hline 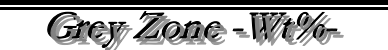 \\
\hline $\mathrm{Cu}(\mathrm{OH})_{2}: 32.3 \%$ \\
\hline $\mathrm{Cu}_{4}(\mathrm{OH})_{6} \mathrm{SO}_{4}: 7.0 \%$ \\
\hline $\mathrm{Cu}_{0.46} \mathrm{Ca}_{0.54} \mathrm{CO}_{3}: 33.3 \%$; \\
\hline $\mathrm{PbSO}_{4}: 4.0 \%$ \\
\hline $\mathrm{ZnO}: 3.7 \%$ \\
\hline $\mathrm{Si}_{2} \mathrm{O}_{3}: 4.6 \%$ \\
\hline $\begin{array}{c}\text { Carbon: } 12.2 \% ; \\
\text { (silicon carbide: } 2.9 \% \text { ) }\end{array}$ \\
\hline
\end{tabular}

Figure 4 "Statua dello Studente": C1s, Cu2p3/2, O1s, Ca2p and Zn2p3/2 curve-fitted regions of the grey zone and Wt\% derived from fitting results reported in Table 1. 
Table 1 "Statua dello Studente": Curve-fitted data of the analyzed regions

\begin{tabular}{|c|c|c|c|c|c|c|c|c|c|c|c|c|}
\hline & Zone & $\mathrm{C}_{\text {carb }}$ & $\mathrm{C}-\mathrm{C}$ & $C_{o x}$ & $\mathrm{CO}_{3}{ }^{2-}$ & $01 \mathrm{~s}$ & $\mathrm{Ca} \mathrm{p}_{3 / 2}$ \#AES & $\mathrm{Cu} 2 \mathrm{p}_{3 / 2}$ & $\mathrm{~Pb}_{7 / 2}$ & S2p & Si2p & $\mathrm{Zn} 2 \mathrm{p}$ \\
\hline $\mathrm{BE}_{\mathrm{s}}$ & GREEN & 282.6 & 285.0 & 286.9 & 289.7 & $\begin{array}{l}529.4 \\
531.8\end{array}$ & $347.4^{\mathrm{a}}$ & $\begin{array}{l}932.9^{c} \\
934.9\end{array}$ & 139.0 & 168.8 & 102.3 & 1022.2 \\
\hline $\mathrm{At} \%$ & & 1.8 & 8.3 & 2.4 & 9.7 & 54.3 & 7.1 & 9.9 & 0.2 & 1.4 & 1.7 & 3.2 \\
\hline $\mathrm{BE}_{\mathrm{s}}$ & GREY & 282.9 & 285.0 & 287.0 & 289.4 & $\begin{array}{l}529.6 \\
531.7\end{array}$ & $347.3^{b}$ & $\begin{array}{l}932.8^{c} \\
934.8\end{array}$ & 138.8 & 168.8 & 102.5 & 1022.0 \\
\hline At $\%$ & & 1.6 & 20.1 & 3.0 & 6.8 & 47.2 & 3.6 & 12.1 & 0.3 & $0.6_{5}$ & 3.6 & $1.0_{3}$ \\
\hline
\end{tabular}

a: \# KE $(C U L M M)=915.8 \mathrm{eV} \alpha^{\prime}=1850.7 \mathrm{eV}$

b: \#KE $(C U L M M)=916.1 \mathrm{eV} \alpha^{\prime}=1850.9 \mathrm{eV}$

c: $\mathrm{Cu}(\mathrm{l})$ : see text

The most prominent peak in the $\mathrm{C} 1 \mathrm{~s}$ region, $\mathrm{C} 1$, at the lower BEs, was assigned to aliphatic carbon set at $285.0 \mathrm{eV}$ and used as an internal standard to correct all binding energies for residual surface charging due to photoemission $[13,14]$.

The $\mathrm{C} 2$ peak at around $287 \mathrm{eV}$ was assigned to $-\mathrm{C}-\mathrm{OH}$ or - $\mathrm{C}$-O species while the $\mathrm{C} 3$ peak in the range 289.4$289.7 \mathrm{eV}$ to $\mathrm{CO}_{3}{ }^{-2}$ in agreement with XPS data on $\mathrm{CaCO}_{3}$ polymorphs [15].

The carbon peak at the lowest BE side, seen at 282.6$282.9 \mathrm{eV}$, mostly evident for the green zone, was attributed to carbide species (http://srdata.nist.gov/xps/) given the concomitant presence of $\mathrm{Si} 2 \mathrm{p}$ peak at $102.2 \mathrm{eV}\left(\mathrm{Si}_{2} \mathrm{O}_{3} /\right.$ $\mathrm{SiC}$ ) in these zones.

\section{Cu2p}

The curve-fitted $\mathrm{Cu} 2 \mathrm{p}_{3 / 2}$ region shows two component peaks plus shake-up satellites. The whole $\mathrm{Cu} 2 \mathrm{p}$ region comprises two components, $2 \mathrm{p}_{3 / 2}$ and $2 \mathrm{p}_{1 / 2}$, due to the spin-orbit splitting for orbital having $l>1$. These two components are well separated (around $20 \mathrm{eV}$ ) so only the $\mathrm{Cu} 2 \mathrm{p}_{3 / 2}$ peaks can be considered for the assignment of copper chemical states: the corrected binding energies, derived from $\mathrm{Cu} 2 \mathrm{p}_{3 / 2}$ curve-fitted regions of figures 3-4, are reported in Table 1 .

$\mathrm{Cu} 2 \mathrm{p}_{3 / 2}$ (1) at $932.8-932.9 \mathrm{eV}$ was assigned to $\mathrm{Cu}$ (I) produced during acquisition (vide infra).

$\mathrm{Cu} 2 \mathrm{p}_{3 / 2}$ (2) at 934.8-934.9eV corresponds, with its shake up satellites, to various $\mathrm{Cu}$ (II) species of the type $\mathrm{CuSO}_{4}, \mathrm{CuCO}_{3}, \mathrm{Cu}(\mathrm{OH})_{2}$. In fact, the quite large peaks width, necessary for curve-fitting, may account for coexistent states very close in energy.

The presence of well evident Auger peaks associated to $\mathrm{Cu} 2 \mathrm{p}$ photoemission, has allowed to derive the Auger parameters, $\alpha^{\prime}$, defined as $\mathrm{Cu} 2 \mathrm{p}_{3 / 2}(\mathrm{BE})+\mathrm{Cu} \mathrm{LMM}(\mathrm{KE})$ [13,14,16-18].

The Auger parameters, near to 1851, as derived from the peak maxima of both signals reported in Table 1, confirm the above assignments.

As said, the small $\mathrm{Cu}$ (I) peak represents the reduction product of $\mathrm{Cu}$ (II) under XPS analysis, in conditions generated by the use of achromatic radiations [19] as ours. We have ascertained this fact by repeat experiments, changing the acquisition time (and order) for the $\mathrm{Cu} 2 \mathrm{p}$ region. The comparison of spectra, here not reported, has given a confirmation of this phenomenon and of a concomitant readjustment of hydrocarbons in the $\mathrm{C} 1 \mathrm{~s}$ region. We have taken it into account by acquiring the carbon and copper regions soon after the wide spectra, and followed the same acquisition order, consistently for the all samples.

\section{Ca2p}

The curve-fitted $\mathrm{Ca} 2 \mathrm{p}$ region shows the spin-orbit doublet, $\mathrm{Ca} 2 \mathrm{p}_{3 / 2}$ at $347.3 \mathrm{eV}$ and $\mathrm{Ca} 2 \mathrm{p}_{1 / 2}$ at $350.7 \mathrm{eV}$, having the right intensity ratio $(2: 1)[13,14]$ thus indicative of only one chemical state or, as for copper, unresolved closely related chemical states.

In fact, for both zones, the $\mathrm{Ca} 2 \mathrm{p}_{3 / 2}$ BEs at 347.3$347.4 \mathrm{eV}$ can be undoubtedly assigned to calcium carbonates [15] but eventual (unresolved) surface oxides, hydroxides or hydrogen carbonates would contribute to the peaks broadening. Given the superimposition of the most intense $\mathrm{Cu}$ LMM signals (and of a secondary $\mathrm{Zn}$ LMM signal) in the same region some influence on the $\mathrm{Ca}$ peaks area can be expected, however, the advantage is that we have an idea of the relative contribution of calcium and copper in the surface depth analysed by XPS and, also, the KE max of the $\mathrm{Cu}$ Auger signal is worthy derived by the curve-fitting results (see Table 1 ).

\section{$\mathrm{Zn} 2 p$}

As for copper, the distance (around $24 \mathrm{eV}$ ) of the $2 \mathrm{p}_{3 / 2} \mathrm{e}$ $2 \mathrm{p}_{1 / 2}$ doublet for zinc is such that only the $\mathrm{Zn} 2 \mathrm{p}_{3 / 2}$ region was curve-fitted. The corrected $\mathrm{BE}$ for $\mathrm{Zn} 2 \mathrm{p}_{3 / 2}$, at $\approx 1022 \mathrm{eV}$, is typical of $\mathrm{ZnO}$. Literature reports on the likely formation of $\mathrm{Zn}_{5}\left(\mathrm{CO}_{3}\right)(\mathrm{OH})_{6}$, hydrozincite, following the $\mathrm{Zn}(\mathrm{II})$ uptake at calcite surfaces [20], however, from the XPS database the binding energy of $\mathrm{Zn} 2 \mathrm{p}_{3 / 2}$ would be lower, at around $1021.6 \mathrm{eV}$, in such a case. Thus, $\mathrm{ZnO}$ was first confirmed, as preferred assignment, given also the correspondence with the $\mathrm{O} 1$ peak at 529.4$529.6 \mathrm{eV}$, O1s region, both regarding the binding energy and the parallel change in intensities. The curve-fitted regions and the results from fitting show this correlation.

\section{S2p, Si2s and Pb4f}

The three signals of this region were quite noisy, as seen in the inset of Figure 2. The detailed regions are not 
reported in figures but the results from curve-fitting are reported in Table 1 and hereafter discussed.

The $S 2 p_{3 / 2}$ and $S 2 p_{1 / 2}$ doublets are very close in energy, around $1 \mathrm{eV}$. Often the $\mathrm{S} 2 \mathrm{p}$ region is well fitted with one single peak just for practical reasons therefore, the peak maximum may show a little variability depending on the curve-fitting choice.

In the energy range of $168.8-169.1 \mathrm{eV}$ sulphur can be assigned to $\mathrm{SO}_{4}{ }^{-2}$ or to $\mathrm{SO}_{3}{ }^{-2}$. Evidence of sulphate reduction to sulphite are reported under XPS analysis [21] but here the signals were of low intensity and thus curvefitted with only one component and assigned to $\mathrm{SO}_{4}{ }^{-2}$.

The corrected position of the $\mathrm{Pb} 4 \mathrm{f}$ doublet derived by curve-fitting, $\mathrm{Pb}_{4} \mathrm{f}_{7 / 2}$ at $138.8-139.0 \mathrm{eV}$ and $\mathrm{Pb}_{4} \mathrm{f}_{5 / 2}$ at 143.4-143.6eV, is compatible with $\mathrm{PbSO}_{4}$ thus confirming the sulphur assignment, however, in both zones, lead is not sufficient to balance the sulphate and, as reported on the listed weighted compounds (Wt\%), the sulphate anions in excess could only be considered as ligands for copper forming mixed complexes with hydroxides.

As for $\mathrm{Zn}(\mathrm{II}), \mathrm{Pb}(\mathrm{II})$ adsorption is reported at calcite surfaces [20]. Thus, $\left(\mathrm{PbCO}_{3}\right)_{2}(\mathrm{OH})_{2}$ could be considered as a likely product to fulfil the mass balance with total oxygen, but again, the binding energy of $\mathrm{Pb} 4 \mathrm{f}_{7 / 2}$ would be lower, at around $138 \mathrm{eV}$.

The S2p and $\mathrm{Pb} 4 \mathrm{f}$ regions lying close in energy can be acquired together as one single region. This region also contains the Si2s peak that could be curve-fitted to give an estimation of the silicon content in both zones. The areas derived from Si2s and Si2p peaks were the same within the fitting errors, as expected using the proper sensitivity factors for the two spectral regions [13,14].

The Si2p/2s areas were found comparable to the carbide peak, $\mathrm{C}_{\text {carbide, }}$ in the green zone while in the grey zone silicon was found mainly in the oxidized form, $\mathrm{Si}_{2} \mathrm{O}_{3}$ : see Table 1.

\section{5}

The O1s region, is fitted with two component peaks at $\mathrm{BEs}=529.4-529.6 \mathrm{eV}(\mathrm{O} 1)$ and $\mathrm{BEs}=531.7-531.8 \mathrm{eV}(\mathrm{O} 2)$, respectively.

The $\mathrm{O} 1$ position in the energy scale is characteristic of oxide species. Among the ones here possible, $\mathrm{ZnO}$ seems the most probable, given the binding energy of $\mathrm{Zn} 2 \mathrm{p}_{3 / 2}$, however, $\mathrm{CaO}$ and $\mathrm{CuO}$ could also be eventually considered. We'll return to this point in the conclusions.

Similarly, the $\mathrm{O} 2$ binding energy corresponds to various oxygenated species, as for example, carbonates, sulphates, hydroxides and so on, practically, having similar BEs and thus hardly discernable by curve-fitting. Hence, the usefulness of O1s peaks is on the use of the total area, for balancing all the oxygenated species there contributing, as said above.
On these bases, the compounds listed on Figures 3-4 are those best matching the required mass balance for the green and grey zones, respectively.

As evident, the copper- containing compounds are those prevailing in both coloured zones. Copper (II) ions are present as hydroxyl- and hydroxyl/sulphate-complexes on the limestone outer surface. Most important, in the subsurface, the $\mathrm{CO}_{3}{ }^{-2}$ anions are always found in excess with respect to $\mathrm{Ca}(\mathrm{II})$ ions, to a different extent for the two zones, thus requiring $\mathrm{Cu}$ (II) ions for the net charge balance. As reported from laboratory experiments on the uptake of $\mathrm{Cu}(\mathrm{II})$ ions at the calcite surface $[22,23]$, the mixed $\mathrm{Ca}_{\mathrm{x}} \mathrm{Cu}_{1-\mathrm{x}} \mathrm{CO}_{3}$ compounds gradually forms following the inclusion of copper ions into the calcite structure. This finding and the related impact on phase c) of the project will be further discussed in the next paragraphs, after having combined the results obtained from both monuments.

\section{'Vittoriano'}

The set of samples taken from the Vittoriano surfaces were analyzed with $\mathrm{AlK} \alpha$ radiation $(1486.6 \mathrm{eV})$ in order to avoid the superimposition of the Auger signals in the $\mathrm{Ca} 2 \mathrm{p}$ region. Spectra were also repeated with the $\mathrm{MgK} \alpha$ radiation $(1253.6 \mathrm{eV})$ to verify if the same elements were detected with both sources and for a better comparison with the 'Student statue' spectra

In Figure $5 \mathrm{a}$, an enlarged view of the 'Vittoriano Entrance' shows the zones where samples were taken for the chemical analysis. In the lower part, Figure $5 \mathrm{~b}$, is the wide XPS spectrum representative of the Vittoriano' samples studied with this surface technique.

From just a qualitative point of view, the labelled $\mathrm{Ca}, \mathrm{Cu}$, $\mathrm{C}, \mathrm{O}$ and $\mathrm{Pb}$ signals indicate that the main elements are the same as those probed for the 'Student' Statue'. The main differences are due to the lack of detection of $\mathrm{Zn}$ and $\mathrm{S}$ and to the presence of $\mathrm{P}, \mathrm{Mg}$ and $\mathrm{K}$ as new elements, unevenly distributed in the various zones. These differences can be due to the different composition of the two limestones and of the attached bronzes; the relative distance bronze-stone and different urban locations of the two monuments could also play a role. As an example, the correlation of phosphorus with the location of the "Vittoriano" zones is clearly evidenced in Figures 6.

In order to fully understand the similarities and differences, the same detailed investigation for each spectral region was performed (see also supplementary figures A-C and relevant captions) and the curve fitting results hereafter discussed, subdivided for each analysed zone, as reported in Table 2 .

\section{Zone 2}

In Figure $6 \mathrm{a}$ are reported the curve-fitted $<\mathrm{Pb} 4 \mathrm{f}$ and $\mathrm{P} 2 \mathrm{p}>$ regions and the corresponding sampling point of the zone 2 , externally located near the pedestrian road. 
a)
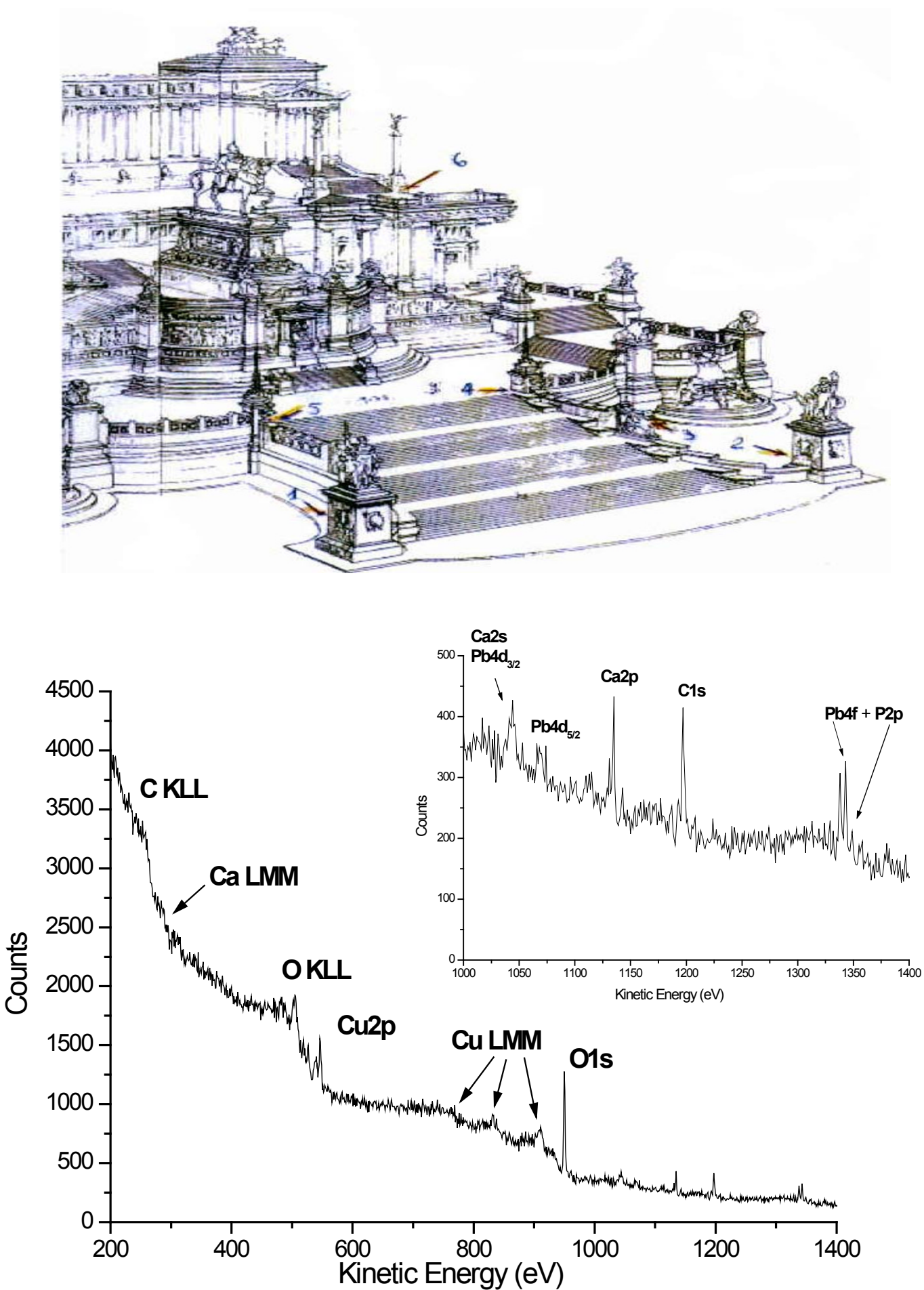

Figure 5 A front view of the 'Vittoriano Entrance' (a) [from: P.L.Porzio (editor), IL VITTORIANO-Materiali per una storia, Soprintendenza per $i$ Beni Ambientali e Architettonici del Lazio, Fratelli Palombi Publisher, Roma, 1986] showing the location of the sampling zones and (b) a typical XPS wide spectrum of the studied Vittoriano' samples. 


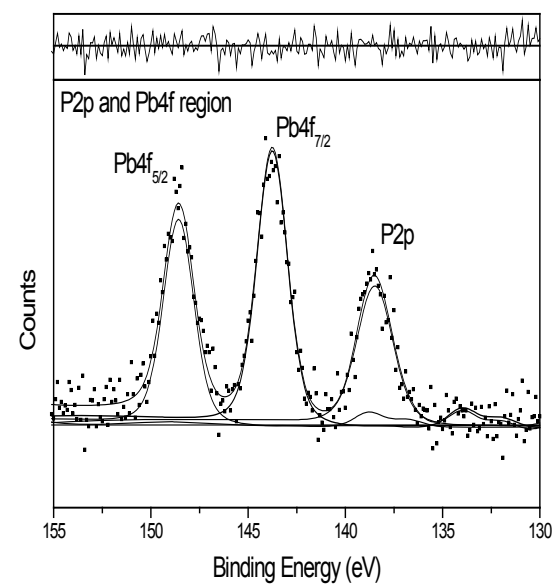

a)
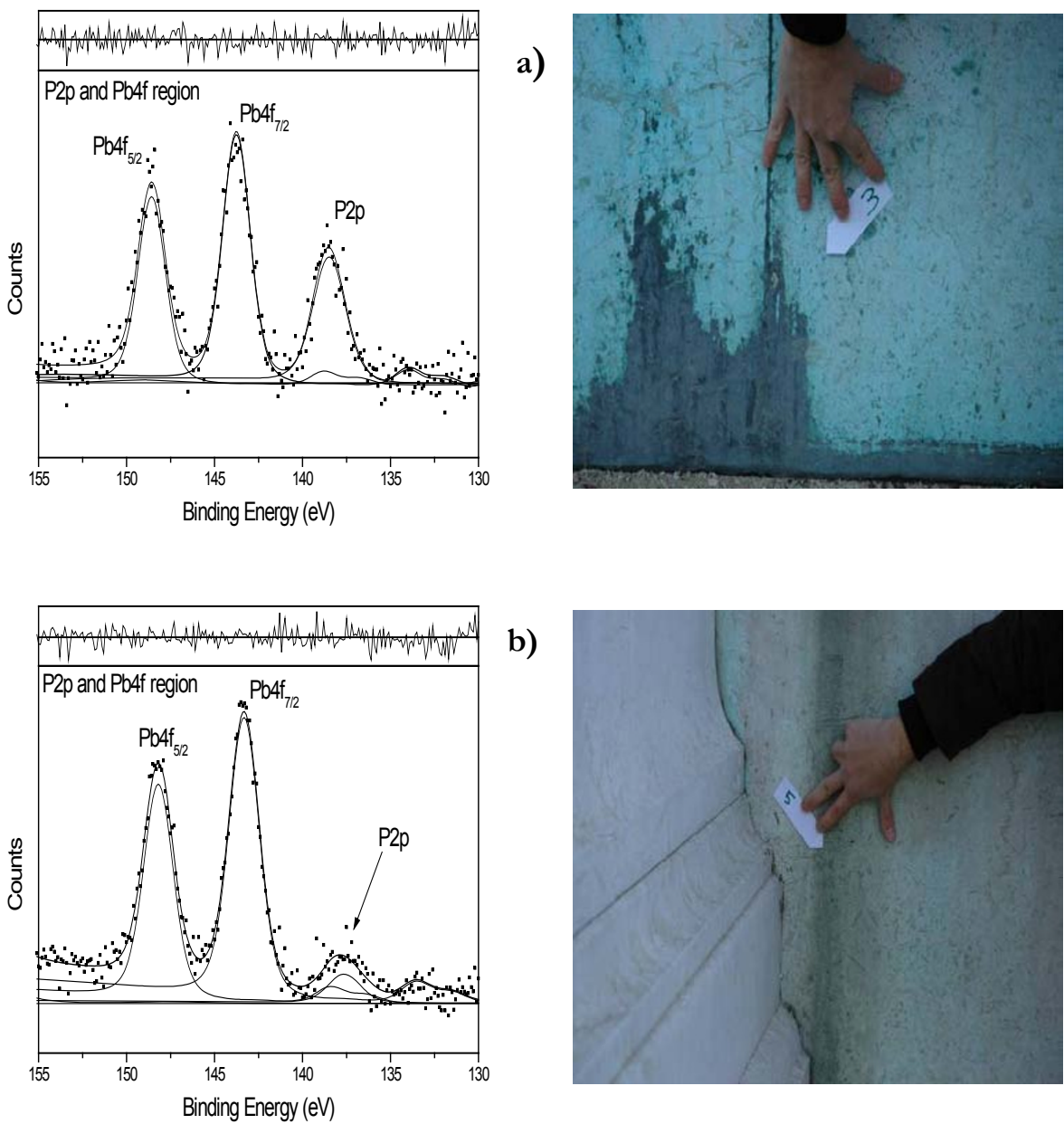

b)
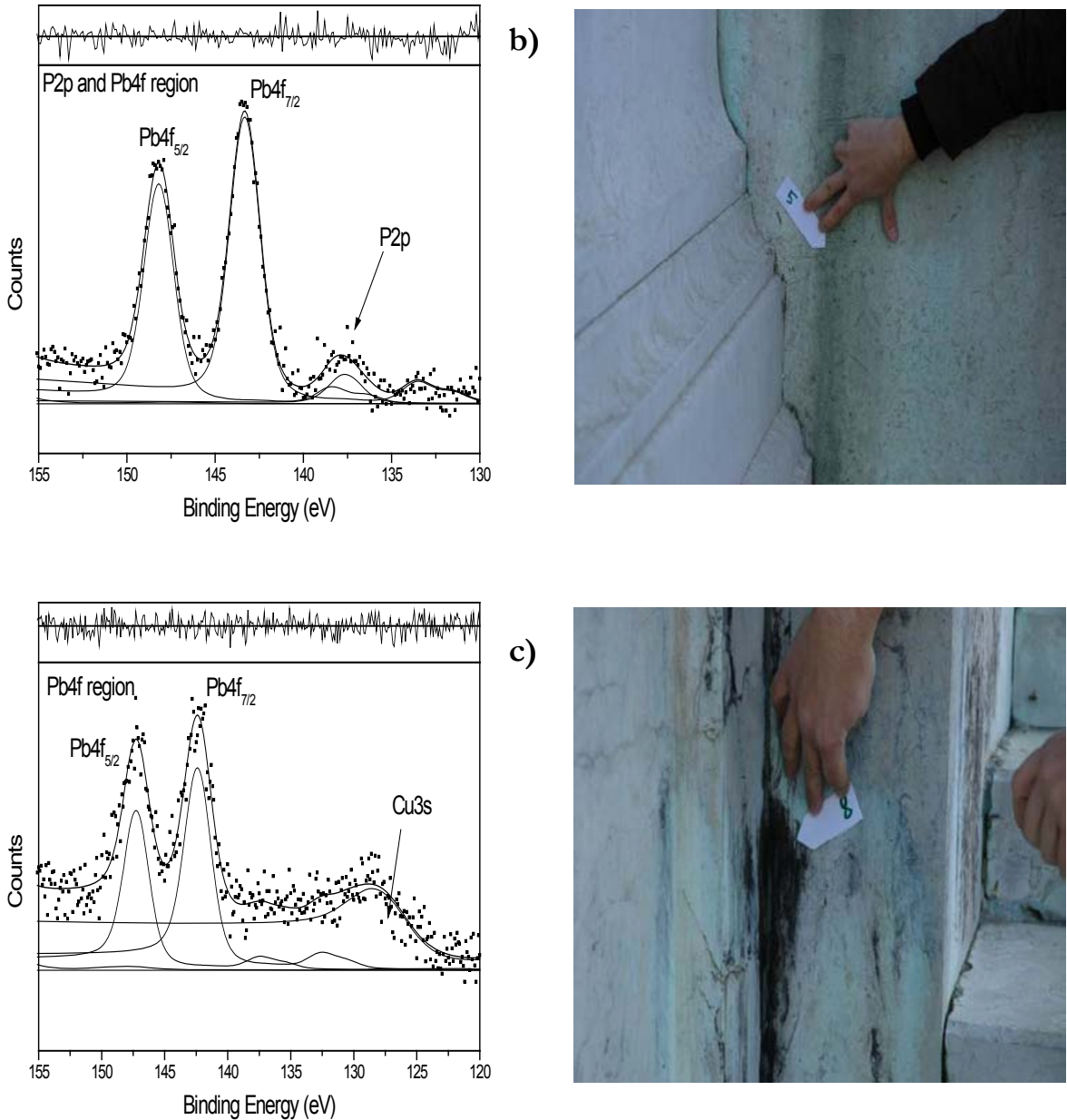

c)

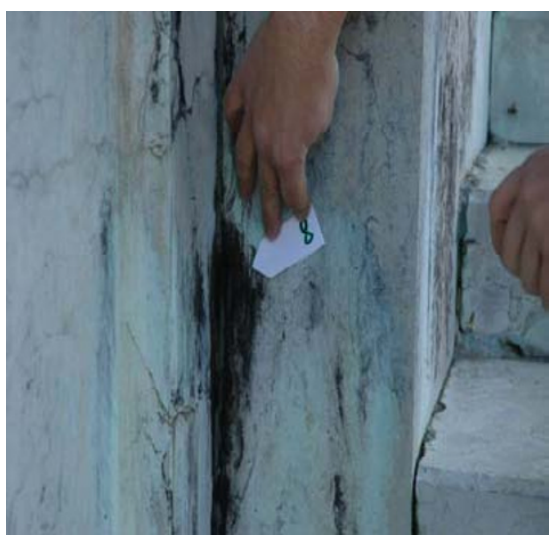

Figure 6 "Vittoriano" sampling points and associated $<\mathrm{Pb} 4 \mathrm{f}$ and P2p> curve-fitted regions: a) the sampling point (3) zone 2- b) the sampling point (5) zone $3-\mathbf{c}$ ) the sampling point (8) zone 5- see curve- fitting results reported in Table 2.

The supplementary figure A, additional file 2, groups the curve fitted regions of the common elements $C$, $\mathrm{Ca}, \mathrm{Cu}, \mathrm{O}$, there detected and shows their chemical states quite similar to those of the previous set as confirmed by results reported in Table 2 . Thus, the discussion reported in previous paragraphs, for each spectral region, applies also here, unless otherwise specified. 
Table 2 "Vittoriano": Curve-fitted data of the analyzed regions

\begin{tabular}{|c|c|c|c|c|c|c|c|c|c|c|c|c|}
\hline & ZONE & $\mathrm{C}_{\text {carb }}$ & $\mathrm{C}-\mathrm{C}$ & $C_{o x}$ & $\mathrm{CO}_{3}{ }^{2-}$ & 01s & $\mathrm{Ca} 2 p_{3 / 2}$ \#AES & $\mathrm{Cu} 2 p_{3 / 2}$ & $K 2 p$ & $\mathrm{P} 2 \mathrm{p}$ & $\mathrm{Pb} \mathrm{f}_{7 / 2}$ & Mg1s \\
\hline $\mathrm{BE}_{\mathrm{s}}$ & 2 & - & 285.0 & 286.4 & 289.7 & $\begin{array}{l}531.7 \\
533.9\end{array}$ & $347.2^{\mathrm{a}}$ & $933.3^{d} / 935.6$ & - & 133.9 & 139.1 & 1304.5 \\
\hline At $\%$ & & - & 10.5 & 3.1 & 8.1 & 58.5 & 6.5 & 6.4 & - & 4.2 & 0.8 & 2.2 \\
\hline $\mathrm{BE}_{\mathrm{s}}$ & 3 & 282.5 & 285.0 & 287.4 & 289.6 & 531.7 & $347.1^{b}$ & 935.0 & - & 133.2 & 139.0 & - \\
\hline At $\%$ & & 1.8 & 29.3 & 2.0 & 6.2 & 42.6 & 6.5 & 9.2 & - & 1.3 & 1.1 & - \\
\hline $\mathrm{BE}_{\mathrm{s}}$ & 5 & 281.9 & 285.0 & 287.1 & 289.7 & $\begin{array}{l}529.5 \\
531.7\end{array}$ & $347.2^{c}$ & 934.3 & 294.6 & - & 137.6 & - \\
\hline At $\%$ & & 3.0 & 13.0 & 3.1 & 8.8 & 50.4 & 5.3 & 15.0 & 0.6 & - & $0.8_{5}$ & - \\
\hline
\end{tabular}

a: \#KE $($ CULMM $)=915.4 \mathrm{eV} \alpha^{\prime}=1851.0 \mathrm{eV}$

b: \#KE $\left(\right.$ CULMM) $=915.8 \mathrm{eV} \alpha^{\prime}=1850.8 \mathrm{eV}$

c: \#KE $(C u L M M)=917.4 \mathrm{eV} \alpha^{\prime}=1851.7 \mathrm{eV}$

d: $\mathrm{Cu}(\mathrm{l})$ : see text

The samples from zone 2 were light blue-green in colour and found to be the most hydrated both within the Vittoriano set and in comparison to those of the 'Student' statue'.

In fact, we see from Table 2 that phosphorus is given at $133.9 \mathrm{eV}$, a position in binding energies compatible with hydrogen phosphate di-hydrated and, consistently, the O1s region shows a shoulder at around $534 \mathrm{eV}$ indicative of hydrating water.

The Mg 1s peak, not reported in figures, is at $1304.5 \mathrm{eV}$ and considered, at first, as a component of the Botticino marble having an intensity ratio of 1:3 with calcium, in agreement with XPS analyses of dolomite surfaces [15]. However, magnesium was found so prominent only in this zone of the Vittoriano, therefore, the possibility of other provenances can not be discarded as will be explained below.

$\mathrm{Ca} 2 \mathrm{p}$ and $\mathrm{Cu} 2 \mathrm{p}_{3 / 2}$ peaks have energies still characteristic of carbonates and hydroxides $\left(\alpha^{\prime} \mathrm{Cu} \approx 1851\right)$, however, the $\mathrm{Cu} 2 \mathrm{p}_{3 / 2}$ is slightly shifted to higher BEs seemingly more influenced by the phosphates anions.

The presence of phosphates, given the location of zone 2, could be ascribed to biological activities: as reported [24], the presence of cornetite, $\left(\mathrm{Cu}_{3} \mathrm{PO}_{4}(\mathrm{OH})_{4}\right)$, was evidenced in studies concerning the effect of bird dropping on outdoor bronzes.

Also lead is found in a chemical state similar to $\mathrm{PbSO}_{4}$, in this case, most likely balanced by phosphate anions. The possibility of $\mathrm{Pb}$-complexes with organic ligands should not be disregarded considering the ubiquitous presence of oxygen-containing species in the carbon regions, however, C1s signals in the range of $288-289 \mathrm{eV}$ due to carboxyls, oxalates or amidic groups were not resolved by curve-fitting.

In summary, considering the mass balance with total oxygen, the surface compounds predominating in this sample are mixed carbonates, hydroxides and hydrated phosphates complexes bound with $\mathrm{Ca}, \mathrm{Cu}, \mathrm{Pb}$ and $\mathrm{Mg}$ ions, regardless of whether the total amount of magnesium comes only from the dolomite of the underneath stone or if traces from biological residues, released by the surroundings, add to the total amount.

\section{Zone 3}

In Figure $6 \mathrm{~b}$ are reported the curve-fitted $<\mathrm{Pb} 4 \mathrm{f}$ and $\mathrm{P} 2 \mathrm{p}>$ regions and the corresponding sampling point of the zone 3 , located at the entrance stairs, above zone 2 .

The supplementary figure $\mathrm{B}$, additional file 3 , groups the curve fitted regions of the common elements $\mathrm{C}, \mathrm{Ca}$, $\mathrm{Cu}, \mathrm{O}$ detected in this confined area, coloured light greywith green streaks, as shown in the picture. Looking at the spectra and at the fitting results reported in Table 2, we see that here $\mathrm{Mg}$ is not evident or better is not quantifiable- in fact we can see its Auger peak outside the carbon region, but not its photoelectron peak at lower KE. Similarly, we notice that phosphorus is strongly reduced in intensity and at a binding energy closer to that of phosphates with no excess of hydrating water.

These findings may be in support of the hypothesized biological threats around zone 2 .

The prominent hydrocarbon components in the carbon region look similar to the grey zone of the student statue, darkening the coloured stains and here obscuring the underlying carbonates even more.

The copper region could here be fitted with one single peak, quite broad to account also for the eventual reduction $(\mathrm{Cu}(\mathrm{I})$ peaks not resolved). Consistently with the low content of phosphorus, its binding energy is lowered to $935 \mathrm{eV}$ a value also similar to the 'Student statue' samples as well as its Auger parameter $(\alpha$ ' $=1850.8 \mathrm{eV}$, Table 2).

The combining of all oxygenated species indicates carbonates, hydroxides and phosphates as complexes for calcium, lead and copper ions. The quite consistent excess of copper (see At\%, Table 2) can only be associated to $\mathrm{Cu}(\mathrm{OH})_{2}$ for achieving the right mass balance with the total oxygen.

\section{Zone 5}

In Figure 6c are reported the curve-fitted $<\mathrm{Pb} 4 \mathrm{f}$ and $\mathrm{P} 2 \mathrm{p}>$ regions and the corresponding sampling point of 
the zone 5 located internally of the upper stairs, slightly out of reach and better sheltered.

The supplementary figure $\mathrm{C}$, additional file 4 , groups the curve fitted regions of the common elements $\mathrm{C}, \mathrm{Ca}$, $\mathrm{Cu}, \mathrm{O}$ composing the black area of this zone 5 . The black stains visible in the image are at the junction of two marble slabs, likely a favourite lane for the corrosion products and pollutants, transported by rains, to accumulate.

Here we see that the carbide component in the carbon region is relatively intense but, differently from the student statue samples, silicon is not detected in the surface area or at least is below the detection limit. The binding energy interval of 281.5-283.7 eV accounts for various silicon carbides of $\mathrm{SiC}_{\mathrm{x}}$ stoichiometry, however, compounds like phenyl- acetylene and cyclic/ unsaturated carbons also are reported to contribute in that region, see NIST database at http://srdata.nist.gov/xps/.

Lead is here at a $\mathrm{BE}$ position of $\mathrm{PbO} / \mathrm{PbO}_{2}$ and phosphorus is below detection, eventually hidden by the background tails of the Cu3s peak. Some traces of oxidized potassium are likely seen, instead. However, the peak at $294.6 \mathrm{eV}$, not resolved by curve-fitting in the two spin-orbit components, can either be ascribed to $\mathrm{K} 2 \mathrm{p}$ for non-stoichiometric oxides or misinterpreted by confusion with energy losses in the $\mathrm{C} 1 \mathrm{~s}$ background region.

More importantly, the lower $\mathrm{Cu} 2 \mathrm{p}_{3 / 2}$ binding energy at $934.3 \mathrm{eV}$ may include the contribution of tenorite $\mathrm{CuO}$ consistently with the satellites peak shape [15] and the change of the Auger parameter now reported at $1851.7 \mathrm{eV}$ (see relevant data in Table 2). Furthermore, the $\mathrm{O} 1 \mathrm{~s}$ region confirms the presence of oxides either with the $\mathrm{O} 1$ peak at $529.5 \mathrm{eV}$ (as it was for $\mathrm{ZnO}$ in the green area of 'Student' statue) and through the mass balance with the oxygenated species.

Interestingly, the black patches seem to be composed of lead oxide (which, as $\mathrm{PbO}_{2}$ Plattnerite, could also contribute to the blackish colour of the patch), mixed calcium and copper carbonate $\left(\mathrm{Ca}_{0.6} \mathrm{Cu}_{0.4} \mathrm{CO}_{3}\right)$ with the excess of copper in form of mixed $\mathrm{Cu}(\mathrm{OH})_{2} / \mathrm{CuO}$ in a ratio of 3:1.

\section{Conclusions}

The most important outcomes can be summarized in the following points:

- the major constituent of the coloured stains on both travertine and Botticino limestone is copper - the presence, always in minor quantity, of the other alloys elements in bronze artefacts is dependent on possible differences in their alloy composition and their relative distance and position with respect to the stone surface $i$. e. zinc was detected by XPS in the basement of the 'Student statue' (travertine) but not in the wall surfaces of the 'Vittoriano' (Botticino limestone). It should also be noted that tin has never been detected in any of the numerous samples that were analyzed from both the monuments.

- copper is present in form of mixed compounds with calcium: hydroxysulfates, hydroxycarbonates, etc. , the relative amount of counter-anions and different degrees of hydration are related to the location of the monuments in the city and, within the same monuments, to the different sampling zones (fully exposed or partially protected areas)

- the colour of the stains (ranging from light bluegreen to grey and dark black) is dependent on the relative amount of the mixed $\mathrm{Cu}$ compounds and on the presence of carbonaceous particulates, for example, black patches were found to be composed of tenorite $(\mathrm{CuO})$ normally quite unstable, tending to transform in hydroxycomplexes, but, in this case, probably stabilized in joint zones made impermeable by carbon-containing contaminants. The presence of Plattnerite, $\mathrm{PbO}_{2}$, could also significantly contribute to the black colour of these stains.

- Other minor components present in the analysed samples, such as oxidized silicon and amorphous carbon indicate either dissolution of argillaceous inclusions of the carbonate slabs and deposition of air-borne particles [25]: their concomitant presence leads to the formation of silicon oxides with reduced binding energies and carbides, as already detected at the interface of rubber/silica composite materials [26].

The obtained results confirm the tendency of copper leaching from bronzes (transformed by corrosion to $\mathrm{Cu}$ (II)) to interact with calcium carbonate and form mixed compound of variable compositions on the surface and sub-surface portions of the limestones. As reported [23], in depth analysis would show the slow formation of a solid solution $\mathrm{Ca}_{\mathrm{x}} \mathrm{Cu}_{1-\mathrm{x}} \mathrm{CO}_{3}$, thus very difficult to be removed without affecting the inner stone structure (calcite). Moreover, the presence of $\mathrm{CuO}$ in black patches should be considered together with the likely influence of waterproof contaminants [27].

\section{Additional material}

Additional file 1: Appendix

Additional file 2: Figure A "Vittoriano": the sampling point (3) of the zone 2 ' and relevant $\mathrm{C} 1 \mathrm{~s}$, Cu2p3/2, O1s and Ca2p detailed XPS regions see curve- fitting results reported in Table 2.

Additional file 3: Figure B "Vittoriano": the sampling point (5) of the zone 3 and relevant C1s, Cu2p3/2, O1s and Ca2p detailed XPS regionssee curve- fitting results reported in Table 2.

Additional file 4: Figure C "Vittoriano": the sampling point (8) of the zone 5 and relevant C1s, Cu2p3/2, O1s and Ca2p detailed XPS regionssee curve- fitting results reported in Table 2. 


\section{Acknowledgements}

Thanks to the 'UniBas' students of the semester courses on Surface Analytical Chemistry for their exercises on XPS curve-fitting

This article has been published as part of Chemistry Central Journal Volume 6 Supplement 2, 2012: Proceedings of CMA4CH 2010: Application of Multivariate Analysis and Chemometry to Cultural Heritage and Environment. The full contents of the supplement are available online at http://journal. chemistrycentral.com/supplements/6/S2.

\section{Author details}

'University of Basilicata, Chemistry Department, Viale Ateneo Lucano 10, 85100 Potenza, Italy. ${ }^{2}$ University of Rome La Sapienza, Chemistry Department, p.le A. Moro 5, 00185 Roma, Italy.

\section{Authors' contributions}

AMS and FL carried out the XPS measurements, fitted spectra and elaborated data and drafted the manuscript in the light of referenced work. They also provided some basic information on XPS in form of a supplementary appendix.

AM, MPS and MLT conceived the overall research, collected samples and selected the most significant ones to be analyzed by XPS; furthermore, basing on their experience and relevant literature, contributed to the understanding of the experimental results and to the optimization and validation of the manuscript.

All authors have read and approved the final manuscript.

\section{Competing interests}

The authors declare that they have no competing interests.

Published: 2 May 2012

\section{References}

1. Chiavari C, Rahmouni K, Takenouti H, Joiret S, Vermaut P, Robbiola L: Composition and electrochemical properties of natural patinas of outdoor bronze monuments. Electrochim Acta 2007, 52(27):7760-7769.

2. Serghini-Idrissi M, Bernard MC, Harrif FZ, Joiret S, Rahmouni K, Srhiri A, Takenouti H, Vivier V, Ziani M: Electrochemical and spectroscopic characterization of patinas formed on an archeological bronze coin. Electrochim Acta 2005, 50(24):4699-4709.

3. Odnevall Wallinder I, Hedberg Y, Dromberg P: Storm water runoff measurements of copper from a naturally patinated roof and from a parking space. Aspects on environmental fate and chemical speciation. Water Res 2009, 43(20):5031-5038.

4. Gaylarde CC, Gaylarde PM, Beech IB: Deterioration of limestone structure associated with copper staining. Int Biodeterior Biodegrad 2008, 62(2):179-185.

5. Ling $H$, Qingrong Z, Min G: Characterization of corroded bronze Ding from the Yin Ruins of China. Corrosion Sci 2007, 49(6):2543-2546.

6. Fitzgerald KP, Nairn J, Skennerton G, Atrens A: Atmospheric corrosion of copper and the colour, structure and composition of natural patinas on copper. Corrosion Sci 2006, 48(9):2480-2509.

7. Turhan $\mathrm{H}$ : Adhesive wear resistance of $\mathrm{Cu}-\mathrm{Sn}-\mathrm{Zn}-\mathrm{Pb}$ bronze with addition of Fe, Mn and P. Mater Lett 2005, 59(12):1463-1469.

8. Laurenzi Tabasso M, Macchia A, Sammartino MP, Visco G: SEM/EDS Analysis of Incrustations Coming From the "Fontana delle Tartarughe" (Turtles Fountain) Located in Rome, Italy. Chemometrics and Multivariate Analysis Applied to Cultural Heritage and Environment Nemi (Rome);8854807656 2006

9. Macchia A, Sammartino MP, Laurenzi Tabasso M: A new method to remove copper corrosion stains from stone surfaces. J Archeol Sci 2011, 38(6):1300-1307, doi: 10.1016/j.jas.2011.01.005. In press, available online.

10. Macchia A, Salvi AM, Sammartino MP, Tabasso Laurenzi M: Stone and bronze in monuments: decay forms and cleaning proposals. Youth in Conservation of Cultural Heritage Italian Chemical Society, Rome;20081124200811252010.

11. Castle JE, Salvi AM: Chemical state information from the near-peak region of the X-ray photoelectron background. I Electron Spectrosc Relat Phenom 2001, 114-116:1103-1113

12. Castle JE, Chapman-Kpodo H, Proctor A, Salvi AM: Curve-fitting in XPS Using Extrinsic and Intrinsic Background Structure. J Electron Spectrosc Relat Phenom 1999, 106(1):65-80.
13. Briggs D, Seah MP: Practical Surface Analysis. John Wiley and Sons, Chichester, U.K.;13: 9780471920816 19901, Appendix 6 and Chapter $5 .$.

14. Briggs D, Grant JT: Surface Analysis by Auger and X-ray Photoelectron Spectroscopy. IM Publications, Chichester, U.K:;1901019047 2003.

15. Gopinath CS, Hedge SG, Ramaswamy AV, Mahapatra S: Photoemission studies of polymorphic $\mathrm{CaCO} 3$ materials. Mater Res Bull 2002, 37(7):1323-1332.

16. Chawla SK, Sankarraman N, Payer JH: Diagnostic spectra for XPS analysis of Cu-O-S-H compounds. J Electron Spectrosc Relat Phenom 1992, 16(1):1-18.

17. Moretti G: Auger parameter and Wagner plot in the characterization of chemical states by X-ray photoelectron spectroscopy: A review. J Electron Spectrosc Relat Phenom 1998, 95(2-3):95-144.

18. Malitesta C, Sabbatini L, Torsi L, Zambonin PG, Ballivet-Tkatchenko D, Galy J, Parize JL, Savariault JM: Copper Speciation by Analytical Electron Spectroscopies: Case of the Intercalation Phase $\mathrm{Cu}_{0.5} \mathrm{~V}_{2} \mathrm{O}_{5}{ }^{*} 0.5 \mathrm{H}_{2} \mathrm{O}$. Surf Interface Anal 1992, 19(1-12):513-518.

19. lijima Y, Niimura N, Hiraoka K: Prevention of the reduction of $\mathrm{CuO}$ during X-ray Photoelectron Spectroscopy Analysis. Surf Interface Anal 1996, 24(3):193-197.

20. Elzinga EJ, Rouff AA, Reeder RJ: The long-term fate of $\mathrm{Cu}^{2+}, \mathrm{Zn}^{2+}$, and $\mathrm{Pb}^{2}$ ${ }^{+}$adsorption complexes at the calcite surface: An X-ray Absorption spectroscopy study. Geochim Cosmochim Acta 2006, 70(11):2715-2725.

21. Squarcialupi MC, Bernardini GP, Faso V, Atrei A, Rovida G: Characterization by XPS of the corrosion patina formed on bronze surfaces. J Cult Herit 2002, 3(3):199-204.

22. Stipp SL, Hochella MFJ: Structure and bonding environments at the calcite surface as observed with X-ray Photoelectron Spectroscopy (XPS) and low energy electron diffraction (LEED). Geochim Cosmochim Acta 1991, 55(6):1723-1736.

23. Schosseler PM, Weahrli B, Schweiger A: Uptake of $\mathrm{Cu}^{2+}$ by the calcium carbonates vaterite and calcite as studied by continuous wave (cW) and pulse elctron paramagnetic resonance. Geochim Cosmochim Acta 1999, 63(13-14):1955-1967.

24. Bernardi E, Bowden DJ, Brimblecombe P, Kenneally H, Morselli L: The effect of uric acid on outdoor copper and bronze. Sci Total Environ 2009, 407(7):2383-2389.

25. Maravelaki-Kalaitzaki P, Bertoncello R, Biscontin G: Evaluation of the initial weathering rate of Istria stone exposed to rain action, in Venice, with Xray photoelectron spectroscopy. Journal of Cultural Heritage 2002, 3:273-282

26. Salvi AM, Pucciariello R, Guascito MR, Villani V, Intermite L: Characterization of the interface in rubber/silica composite materials. Surf Interface Anal 2002, 33:850-861.

27. Rai US, Singh RK: Effect of polyacrylamide on the different properties of cement and mortar. Mat Sci Eng A-Struct 2005, 392(1-2):42-50.

doi:10.1186/1752-153X-6-S2-S10

Cite this article as: Salvi et al.: XPS characterization of (copper-based) coloured stains formed on limestone surfaces of outdoor Roman monuments. Chemistry Central Journal 2012 6(Suppl 2):S10.

\section{Publish with ChemistryCentral and every scientist can read your work free of charge \\ "Open access provides opportunities to our colleagues in other parts of the globe, by allowing anyone to view the content free of charge." W. Jeffery Hurst, The Hershey Company. \\ - available free of charge to the entire scientific community \\ - peer reviewed and published immediately upon acceptance \\ - cited in PubMed and archived on PubMed Central \\ - yours - you keep the copyright \\ Submit your manuscript here: \\ http://www.chemistrycentral.com/manuscript/<smiles>c1ccccc1</smiles> ChemistryCentral}

